espaço aberto

[ LILIAN ALVES ]

Graduada em Moda pela Faculdade Santa Marcelina, em São Paulo. Atualmente, trabalha com moda e seus recortes diversos: moulage, estamparia, escrita, fotografia, confecção. Coempresária das marcas Lilian Alves e HitList.

E-mail: lilialvestilo@yahoo.com.br

\title{
O sopro da moda e nossas [eco]lógicas [sus]tentações
}

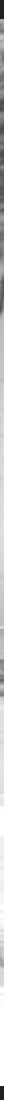

Cidade Art-CircuLar. Foto: Lilian Alves.

Durante uma pequena discussão dentro de um grupo virtual de debates ${ }^{1}$ relacionados ao tema Lixo (do qual participam ativistas e ONGs da causa), peguei-me considerando o amargo e o doce da "moda ecológica" e da "vida tecnológica".

Não, eu não estou falando de moda ecológica nivelada no teor "ecobag". Penso na intersecção entre as propostas de moda ecológica, a moda socialmente comprometida, e o terceiro setor, uma fusão em pequena escala que parece ter conquistado grandes e belos resultados, embora ainda caros ao consumidor. Atividade que tem unificado comunidades e realçado culturas locais país afora. E reflito sobre a dificuldade de levar de modo consistente as mesmas questões para a grande indústria e em como elaborar melhor a informação para o consumo em massa, força seletiva, financeira, motriz, chamada estranhamente de "consumidor final". Como final? Se é ele que está no foco do designer da indústria desde o começo do seu trabalho?

Especialistas em questões ambientais não estão completamente errados em julgar negativamente as soluções de superficie da "ecomania" que só têm feito vestir empresas e pessoas num fino véu marketeiro para subliminarmente manter aquecida a roda gigante do consumo. Mas esses experts podem também pecar ao desconsiderar (superficialmente) o caráter positivo daquelas iniciativas que envolvem soluções ecológicas na moda 
e, ao mesmo tempo, melhoram o cotidiano de pessoas, abrangendo então o termo "sustentabilidade". Parece notório que a única forma de ser puramente ecológico seria não existirmos. Existir é, por excelência, igual a consumir. Não importa se o consumo é de bolsas feitas de tecido reutilizado ou com tecnologia de ponta, tudo será lixo se continuarmos tratando da renovação das emoções em ciclos temporários, o que parece um pouco longe de se acalmar. Assistimos hoje a um desenvolvimento desenfreado de novos itens que possam satisfazer sonhos e, paralelamente, levar um selo "eco" que justifique o encarecimento do produto e a segmentação de público.

Na contramão dessa realidade, há alguns grupos que atuam contra o consumo desnecessário, prezando a troca, por exemplo. Mais comuns na Europa, embora existam no Brasil, é fato. Fato também que praticamente toda a estrutura de vida humana comum está baseada no ter, no sentir através do ter. E não se trata apenas de ter coisas, roupas ou objetos novos ou usados, falo também em "ter a presença", "ter o toque", "ter as sensações" e "ter acesso". E para se ter acesso, seja a um bom dentista, seja a informações e cultura, é necessário basicamente ter o capital para acessar e/ou adquirir. Ambição, tentação e "eco-nsciência"... como conciliar esses polos quando nosso desejo, além da "coisa" que queremos vestir, ouvir, sentir, estende-se em linha vertical um pouco mais profundamente?

Nos trabalhos que desenvolvo, essa pergunta sempre vem e vai: "E você utiliza malha PET?". E se a resposta é "não", vejo o rosto desmontar-se decepcionado. É evidente o exercício cíclico ditatorial da moda ordenando algo como "Seja eco você também!". Libertário é conceito que não se aplica (ainda) ao sistema da moda. Isso já resultou na vulgarização dos termos "sustentabilidade" e "ecologia" a tal ponto que, ao consumir uma camiseta "eco" de fio PET, por exemplo, o comprador (meio informado) sente-se totalmente inserido nessa boa onda, mas... afinal, qual é o nível real de comprometimento social e ambiental que esse ato tem? Nas profundezas do oceano de garrafas de refrigerantes e afins, quem vislumbra que a indústria de fios só pode assimilar essa tecnologia porque há quantidade/volume de plástico convertido em cones suficientes para abastecer seus teares e fabricar toneladas de malha?

Outro exemplo vivenciado há poucos anos aconteceu dentro do complexo contexto do mercado fabril nacional de marcas renomadas, quando ocorreu o que gosto de chamar de "bamboom". Isso foi quando (res)surgiu a viscose de fibra de bambu, uma febre legitimada pelas tags apinhadas de informação sobre suas generosas qualidades "ecológicas". Não domino tecnologia têxtil, portanto, não me atrevo a discorrer se o tecido feito de fibra de bambu tem/teve funções ecológicas ou não, pois nas pesquisas com fabricantes não consegui encontrar uma resposta definitiva. Sei que é uma fibra celulósica sintetizada como qualquer outra viscose, daí a possibilidade de ter nível zero em quesito ecologia é enorme, caso o fabricante de fios e a malharia ou tecelagem não controlem a emissão de gases ou 0 tratamento de efluentes, por exemplo.

A ânsia do mercado fashion em utilizar as malhas com essa fibra causou escassez de matéria-prima em certo momento. Fios não chegavam aos portos, as entregas das grandes malharias começaram a atrasar e houve um pequeno colapso. Lembro-me bem de chefes, gerentes comerciais, representantes e estilistas irritados, tensos, esbravejando, perdendo vendas, perdendo vendas! Onde está a verdade de uma roupa feita de tecido ecofashion?

Falo de uma verdade enforcada em calendários curtos que, em diferentes esferas, são guiados pelas viradas das vitrinas no exterior e por designers em busca da definição e validação do que será plausivel de comércio em suas respectivas coleções. Esse hábito sufoca todo o setor, gerando uma reação em cadeia de profissionais e prestadores de serviço lutando contra o tempo.

Nessas condições reais, há como se construir identidade e oferecer verdadeira cartografia de sustentabilidade e ecologia dentro de cada blusa de bambu costurada?

Sobre o que chamo de "moda eco sem lógica", venho advertindo os pensamentos mais cinzentos, acalmando-os e lembrando-os que é da nossa natureza produzir coisas. Impossivel descartar nossas habilidades, criatividade, inventividade para sermos totalmente ecológicos. Como não nos utilizarmos desses recursos/dons/talentos que nos impelem a produzir coisas em todas as esferas de atuação o tempo todo? 
Parece impraticável, e mais ainda num momento em que o ciberespaço ampliou a noção de vida de um modo que parece irreversivel. Somos invocados a estar em todos os lugares e, ao mesmo tempo, em lugar nenhum. Há uma convocação implícita a que se realize muito, pois ali está a grande vitrina, diante de milhares de olhos e mentes prontos para absorver, regurgitar, comprar (o objeto ou a ideia), dividir, compartilhar. Acompanho considerações de estudiosos e amigos sobre o futuro (i)material, principalmente sobre a força das redes sociais que, em resumo, afastam aproximando com a mesma intensidade que aproximam afastando, recriam incessantemente nossas obsoletas noções de conectividade, possibilitam formas de relacionamento antes desconhecidas. Também se questionam o imediatismo, os níveis de dependência eletrônica, o poder de decisão para compra, o enfraquecimento da opinião pessoal (uma vez que o indivíduo é bombardeado de informações externas, conversando muito pouco com o próprio querer). Mas essas são as visões mais catastróficas da coisa. Seria saudável vislumbrar outras possibilidades.

Com a licença poética do devaneio ficcional, como seria então um planeta em que as pessoas se tocassem tão pouco? Haveria a possibilidade de, uma vez que estivessem obrigatoriamente mais consigo mesmas, entrarem num processo de reconhecimento e, assim, começarem a rever as próprias escolhas? Informarem-se em rede para somar dados de conhecimento aos estímulos individuais de emoção...? Isso já ocorre em pequenas amostragens? Seria possivel acontecer em escala macro? E pelo lado de lá do molde, o que passaria a significar o toque do têxtil sobre a pele, numa provável escassez de longos abraços e periodos de pele sobre a pele? Que importância teria uma roupa, cenário do corpo, que fornece sensações de calor, aconchego e outras emoções, complementando as emoções que não deixam de existir entre indivíduos que se comunica(ria)m na maior parte do tempo virtualmente? Teríamos uma roupa ou ilusão de roupa? Imagine uma roupa capaz de transmitir e receber/trocar impulsos através do celular, por exemplo, objeto que já se tornou para muitos praticamente uma extensão do corpo (tanto dentro quanto fora do perímetro urbano). E o que isso teria de ecológico? Não sei. 0 futuro depende da forma como as coisas serão pensadas, como as crianças serão "in-formadas". Tudo, e até o avanço tecnológico, caso não haja também um colapso das redes (só para não desperdiçar o clima apocalíptico...), pode ser "consciente" e pode ser verdadeiramente ecológico. Talvez as pessoas voltem a desenvolver suas habilidades com plantio, lavoura, jardinagem, a tecer soluções próprias para cobrir o corpo... que parecem tarefas menos maléficas para o planeta. $\mathrm{Ou}$, talvez, algumas tribos ainda intocadas já tenham chegado ao contato telepático e riam do nosso deslumbramento perante tudo isso. Talvez.

0 que resta é a vontade de deparar com menos hipocrisia ao observar o mercado de moda como eterno vilão aqui e ali.

E, olhando agora para o espelho, para que as modas sustentáveis/ecológicas que estão em situação "tomara que caia" não escorreguem de vez, seria importante tocar/formar mais pessoas-peças nessa engrenagem que reconheçam de modo transparente os limites comerciais do setor para, em acréscimo às técnicas sustentáveis e ecologicamente corretas, desenvolverem formas provocativas que incitem a indústria a libertar outras potencialidades que podem ser transformadoras, estimulando o consumidor (adulto e jovem) a participar, escolhendo melhor se e o que será consumido, numa espécie de autocoleta seletiva, recriando uma verdadeira malha orgânica de ações.

Por isso uma generosa colherada de louvor aqueles que fazem moda verdadeiramente projetada, modos de moda um pouco menos nefastos do que a maioria das coisas que são produzidas, em grande ou pequena escala. Não importa que não seja primariamente ecológico, há momentos em que reconhecer um processo dignificante pode valer tanto quanto a matéria-prima orgânica ou reutilizada. Há momentos em que a beleza histórica que uma peça de vestir traz consigo, impregnada de toque de mãos que a construíram, desperta emoções positivas que são uma contribuição para o futuro do planeta. Há esses momentos. 